\section{Antofagasta 2010: ¿norovirus y Escherichia coli entero toxígenica?}

\author{
Apreciado Sr. Editor:
}

Deseo felicitar a los autores Díaz y cols., por su importante artículo "Brote de gastroenteritis aguda en la Región de Antofagasta”, Chile 2010” Rev Chilena Infectol 2012; 29: 19-25, y al mismo tiempo comentar algunos de sus resultados.

En la Discusión del artículo se indica que en esta epidemia de diarrea aguda el norovirus genogrupo II sería el “agente principal causal” de la epidemia ya que él se demostró en las "muestras clínicas y ambientales”. Sin embargo, en los Resultados se indica que de las 196 muestras analizadas por el laboratorio de la Universidad de Chile 68 (35\%) tenían norovirus y 70 (36\%) tenían Escherichia coli enterotoxigénica (ECET) y que 25 muestras (13,5\%) tenían ambos patógenos. Estos resultados sugerirían que la diarrea aguda podría ser el resultado de infección por estos dos patógenos de manera conjunta o independiente. La relevancia de Escherichia coli en la etiología de esta epidemia sería también sugerida por las muestras analizadas en los laboratorios del ISP ya que en ellas se encontró E, coli diarreogénica en 454 (63,7\%) de 712 muestras.

La hipótesis de la relevancia de $E$. coli enterotoxigénica como un agente etiológico más en esta epidemia recibiría apoyo con la identificación de ECET en las 454 muestras analizadas en el ISP y que fueron positivas para E. coli diarreogénica, designación que incluye por lo menos a seis grupos de E. coli capaces de producir diarrea ${ }^{1}$. E. coli diarreogénica fue también encontrada en una muestra de alimentos. Desde el punto de vista epidemiológico, sería interesante saber también si esta ECET es única y nueva en Chile o pertenece a grupos que ya circulaban con anterioridad en el país ${ }^{1,2}$. Los autores, al parecer le dan gran peso al hallazgo del mismo norovirus II en muestras ambientales (5) y clínicas (20/203) para sustentar su rol en la causalidad de esta epidemia; sin embargo, en el trabajo no dan información respecto de la búsqueda de ECET en muestras ambientales y del tipo de norovirus encontrado en las muestras clínicas analizadas en la U. de Chile. También el número de muestras ambientales (5) analizadas pareciera ser exiguo para poder establecer una correlación estadística estrecha entre la presencia de norovirus en ellas y por lo menos las 31.036 infecciones sintomáticas. La ECET está generalmente ausente de la microbiota normal del intestino humano y su importante presencia en estos pacientes sugeriría también su rol etiológico en esta diarrea². Como el rol causal de ambos patógenos podría haber sido definido en estos pacientes por la búsqueda de anticuerpos indicadores de una infección reciente, sería interesante saber si existe una colección de suero de ellos para hacer estos estudios a futuro.

Respecto de la curva epidemiológica de la Figura 1, los autores indican que "refleja una fuente común continua, con transmisión de persona a persona” lo que apoyaría la etiología por norovirus de esta epidemia. Sin embargo, una curva epidemiológica similar podría ser producida por una fuente común de infecciones por norovirus o ECET que se prolonga a través del tiempo por la inhabilidad de corregir oportunamente los factores que la provocaron (ver mas adelante). La epidemia comenzó en los primeros días de marzo y se adjudicó al terremoto del 27 de febrero de 2010, la falta de hipoclorito de sodio para clorar las aguas servidas, pero los autores señalan que ya el 2 de marzo de 2010 habría habido casos excesivos de diarrea aguda en algunas instituciones de la región. Como el período de incubación de la diarrea por norovirus y ECET es de varios días, esto sugeriría que el problema existía ya antes del terremoto.

La carencia de hipoclorito señalaría una gran improvisación de la compañía sanitaria que trata las aguas servidas ya que indicaría una carencia total de almacenamiento de este químico para cubrir inesperadas eventualidades, incluso antes del terremoto. Esto además indicaría una ausencia de la función fiscalizadora de los organismos gubernamentales encargados de controlar estas actividades para proteger la salud de la población ${ }^{3}$. Según la información disponible, la propia empresa reconoció disminuir el nivel de cloración en sus plantas de tratamiento y que además falló en dar aviso oportuno a la autoridad sanitaria de este problema $^{4,5}$. La empresa solicitó a la autoridad sanitaria disminuir el nivel de cloración el 10 de marzo de 2010, en plena curva ascendente de la epidemia (Figura 1) y la autoridad reacciona ante este hecho solamente el 22 de marzo de 2010, en la cúspide de la epidemia, y al menos una semana después del comienzo de ella ${ }^{5}$. Como comento arriba, este retraso podría explicar la extensión de epidemia en el tiempo y la curva epidemiológica de ella (Figura 1).

Espero que el trabajo de Díaz y cols., y estos comentarios ayuden a clarificar las aparentemente complejas causas de esta epidemia que afectó a miles de personas y ayuden también a mejorar la prevención de contingencias similares en el futuro, incluyendo una fiscalización oportuna y adecuada del Estado en estos procesos que son de su responsabilidad. Una de las lecciones de esta epidemia, es que sin los controles y la fiscalización adecuada, las plantas de tratamiento de aguas servidas posibilitan la exposición de la población a patógenos de transmisión fecal oral y la ausencia de una respuesta rápida del Estado prolonga innecesariamente estos negativos procesos.

\section{Referencias}

1. DuPont H L. Bacterial diarrhea. N Engl J Med 2009; 361: 1560-9.

2. Agüero M E, Reyes L, Prado V, Ørskov I, Ørskov F, Cabello F C. Enterotoxigenic Escherichia coli in a population of infants with diarrhea in Chile. J Clin Microbiol 1985; 22: 576-81.

3. Cabello F C. Los roles del ambiente, de la higiene, de la epidemiología y de las vacunas en el desafío de las enfermedades infecciosas. [The roles that the environment, the sanitary conditions, the epidemiology and vaccines play in the challenger of infectious diseases]. Rev Chilena Infectol 2010; 27: 565-9.

4. Anónimo. Disponible en: http://www.zarey.cl/seremi-de-salud-deantofagasta-multa-a-planta-de-tratamiento-de-aguas-servidas-con-500-utm/

5. Anónimo. Disponible en: http://www.terram.cl/index.php?option=com_ content\&task=view\&id=5475 